\title{
TOP, AN EXAMPLE OF COMPLEX APPLICATION CONTROLS
}

\author{
M. Korver RA \\ Internal Audit Department \\ De Nederlandsche Bank N.V. \\ Westeinde 1 \\ 1017AB Amsterdam \\ The Netherlands \\ Telephone +31205243839 \\ FAX +31205242505 \\ E-mail m.korver@dnb.nl
}

\begin{abstract}
Security and control measures can be implemented as user controls, application controls or general controls. To safeguard the integrity of a database, general controls may be relied on. Or is it, for instance for highly critical applications, necessary to take additional measures in the form of application controls in the application itself ? Based on a risk analysis, in which risks were identified and measures taken to cover these risks, the Dutch Central Bank decided that additional application controls in the form of control totals were necessary. To realize these control totals a separate Control subsystem was designed and implemented. This document describes the control subsystem which is implemented in the payment system of the Bank.

This paper will first give a overview of the payment system of the Dutch central bank. In the second section will be described how is dealt with quality assurance on security and control during application development. In the sections 3 to 9 the control subsystem is specified in detail.
\end{abstract}

\section{Keywords}

Risk analysis, quality assurance, standards on security and control, application controls, control totals, financial transactions. 


\section{OVERVIEW OF TOP}

\subsection{Flow of payments in the Netherlands}

In November 1997 the payment system of the Dutch central bank, called TOP, became operational. The system is an automated real-time gross-settlement system. A major function of the payment system is to facilitate funds transfers to the participants in the system. As part of this function the Bank processes payments, totalling tens of billions of guilders each day, using an automated large-value settlement system.

Different kinds of payments are processed through TOP. The following table shows the average number of transactions per day and the average amount per transaction (in Dutch guilders).

Table 1 Average number of transactions per day and average amount per transaction

\begin{tabular}{|l|c|c|c|c|}
\hline & $\begin{array}{l}\text { Average } \\
\text { number of } \\
\text { transactions } \\
\text { per day }\end{array}$ & $\begin{array}{l}\text { Average } \\
\text { amount per } \\
\text { day } \\
\text { (in billion } \\
\text { NLG) }\end{array}$ & $\begin{array}{l}\text { Average } \\
\text { part in total } \\
\text { number in } \\
\%\end{array}$ & $\begin{array}{l}\text { Average } \\
\text { part in total } \\
\text { amount in } \\
\%\end{array}$ \\
\hline Retail payments & 7.000 .000 & 6,9 & 99,55 & 5,3 \\
Urgent retail payments & 18.000 & 3,0 & 0,26 & 2,3 \\
$\begin{array}{l}\text { Settlement of trades of the } \\
\text { Amsterdam Exchange } \\
\text { (wholesale) }\end{array}$ & 2.800 & 38,2 & 0,04 & 2,8 \\
Interbank payments & 1.100 & 38,2 & 0,02 & 29,5 \\
Non-resident payments & 9.500 & 77,9 & 0,13 & 60,1 \\
\hline
\end{tabular}

Retail payments are processed by Interpay, a clearing house founded by the commercial banks. All commercial banks, as well as large business clients, have a data communication connection with Interpay. Clients of commercial banks may submit their transactions to these banks by means of special forms or by data communication. All transactions of Automated Teller Machines are also submitted to Interpay.

Interpay stores and forwards the transactions received to its clients (commercial banks and large business clients). The bulk of this information is also presented on tape or by cartridge. Every day, Interpay calculates the outstanding balances of the commercial banks. Once a day, these outstanding balances are settled in TOP. 
In addition to normal retail payments, the systems and infrastructure described are also used for urgent retail payments. These kinds of payments have a maximum of 10 million Dutch guilders. These orders are advised to the ultimate benificiary based on the guaranteed settlement by the end of the day in TOP within an hour of being submitted.

Figure 1 Overview of the payment infrastructure in the Netherlands

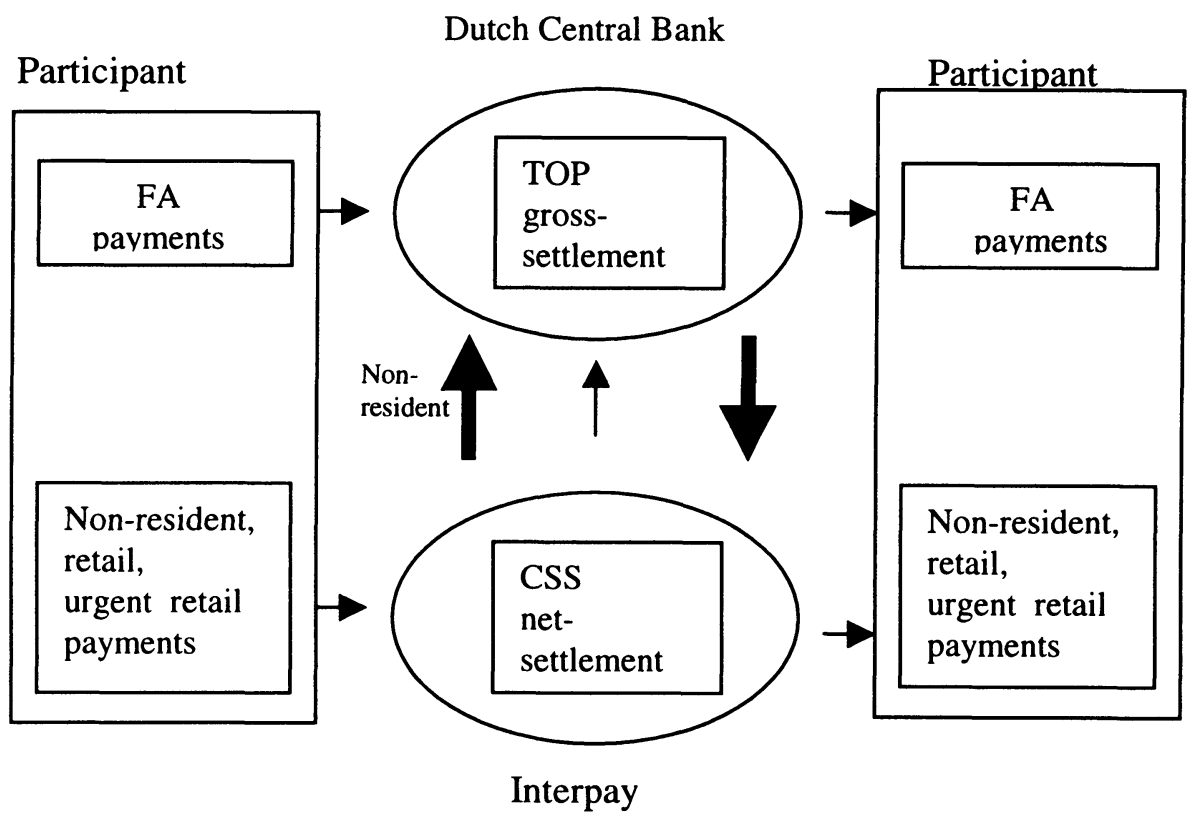

As the overview of the payment infrastructure shows, FA payments are sent directly from the participant to the Dutch Central Bank. The non-resident payments are routed via the network infrastructure of Interpay. Interpay routs the non-resident payment orders to the Dutch Central Bank. The retail and urgent retail payments are processed by Interpay where net settlement takes place. The outcome is sent to the central bank to be cleared.

\subsection{Participants in TOP}

There are about 300 account holders in the Dutch Central Bank's payment system. These include:

- commercial banks

- Ministry of Finance

- Agency of the Ministry of Finance

- interbank clearing house (Interpay) 
- other central banks

- international development banks

The latter two account holders do not have an on-line connection with TOP. Their payment orders are sent to the Dutch Central Bank, where the input is processed by the Payments Department.

\subsection{Input and output}

Orders can be sent to TOP via the TOP end station (TES, which is a dedicated PC), SWIFT for cross-border payments (TARGET), hostlink connection, tapes/cartridges and paper. Information from TOP sent to the participants is received by the TOP end station, hostlink connection, SWIFT and paper.

\subsection{TOP subsystems}

TOP comprises eight different subsystems. This paragraph briefly describes the subsystems with the most relevant functions.

\section{Pre-processing subsystem}

In this subsystem the messages from all participants are received. These can be individual messages, tapes and batches. After having carried out controls like authentication, reliability, format and layout, etc., the messages are processed further. The tapes and batches are unpacked and transformed into individual messages.

\section{Transaction-processing subsystem}

This subsystem contains among other things the functions for the settlement of the payment orders and the queuing mechanism. Also, controls like access control to the account which has to be debited and the check of sufficient cover are carried out.

\section{Post-processing subsystem}

In this subsystem all the output is made ready for sending to the participants. This can be done by individual messages, but also batches and tapes can be formed.

\section{Control subsystem}

The Control subsystem has links with the three subsystems listed above. Information about the processing is written to the Control subsystem. With this information the Control subsystem executes reconciliation controls during the working day. In this paper this subsystem will described in greater detail. Figure 2 shows the relation between the Pre-processing, Transaction-processing and Post-processing subsystems and the Control subsystem. 
Figure 2 Relation between the Pre-processing, Transaction-processing and Post processing subsystems and the Control subsystem

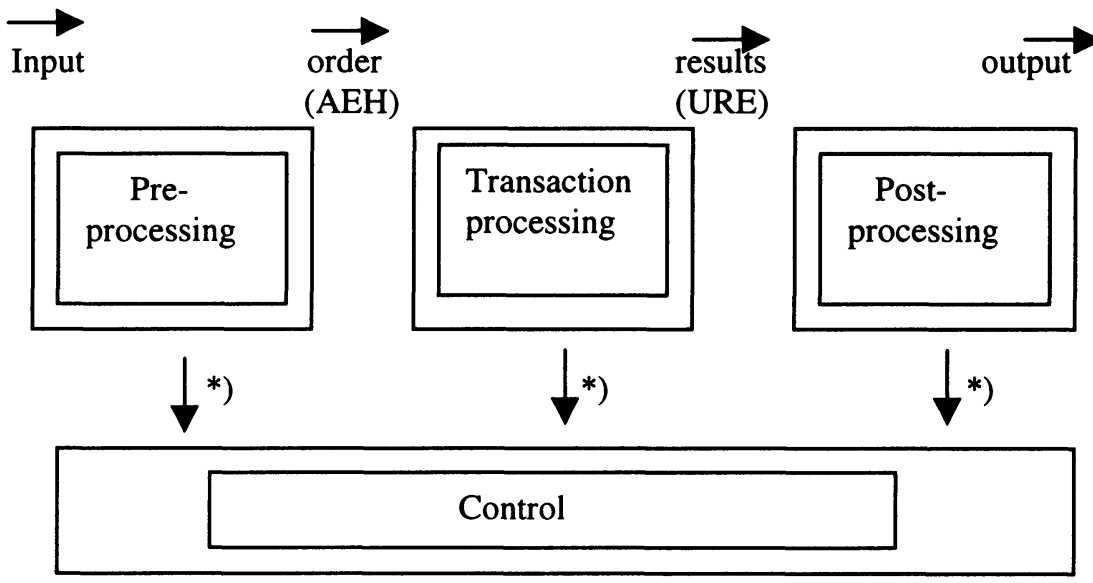

*) Information about the processing, e.g. a change of status of the transactions, is written to the Control subsystem.

To provide a complete overview of TOP, the other subsystems are described very briefly:

Maintenance of permanent data subsystem: this system contains the functions to input, change or delete permanent data.

Periodical processing subsystem: this subsystem contains the functions for housekeeping purposes at the end of a working day, week, month or year. Interest and costs subsystem: this subsystem periodically calculates interest and costs, changes these into orders and offers them to the Transaction subsystem for further processing.

Inquiry subsystem, this subsystem processes the inquiries made by participants.

\subsection{Environment}

TOP application is operational with DB2 as a database management system. General controls such as access control (RACF) and problem and change management procedures are in place. 


\section{QUALITY ASSURANCE ON SECURITY AND CONTROL}

\subsection{General}

The Dutch Central Bank is well aware of the necessity of quality assurance on security and control during the development of applications. To ensure that the right level of measures is included in the application, a project organization is implemented in the Bank and standards on security and control are issued. The standards describe the steps that must be taken to make sure that the risks which can be defined for the application are identified and covered by the appropriate measures. The standards have to be followed by the employees who develop the application, and are also used by the system auditors of the Internal Audit Department while performing the audits.

\subsection{Standards on security and control}

The standards regarding the security and control can be clarified as follows.

\section{Structured approach}

The main theme is the risk analysis. During the development of the application, risks are identified and measures are taken to cover these risks. When the development of the application makes progress, the risks are identified in greater detail. The risk analysis is subdivided into a number of different steps, which are described below.

\section{System characteristics}

A brief description is made of the application, highlighting the most important characteristics. Attention must be given to the quality criteria of

- reliability

- controllability

- confidentiality

- continuity

- authorization

The description has to point out where the risks could be. Answers must be found to questions such as: Is it a financial system? Are the data which are processed confidential?, etc. Based on this description a first, global classification is made of the critical character of the system. The classification can be high, medium or low. In the standards on security and control criteria are mentioned which will help to classify the application.

The result of the classification of the application is mapped with the platform classification. All the platforms used within the Dutch Central Bank are classified. These platforms are PCs, local area networks, mid-range computers and main 
frames. It is specified for these platforms what the standard level of security and control is. This is done for the above mentioned quality criteria and classified in high, medium and low. In this way it is easy to see whether the application security requirements meet the standard security measures of the chosen platform. If this is not the case for one or more of the quality criteria, additional measures are necessary or another platform has to be chosen.

\section{Risk inventory}

In this step the risks are identified in much greater detail. The risk analysis is conducted during the stages of development 'definition study', 'global design' and 'detailed design'. During the development of the system, the risk analysis is developed from its global nature (definition study) into a detailed product (detailed design). Table 2 presents the relationship between the steps of the risk analysis and the relevant phase of system development.

Table 2 relationship between the risk analysis and the phase of system development

\begin{tabular}{|l|c|c|c|c|c|}
\hline & $\begin{array}{l}\text { Informa- } \\
\text { tion plan }\end{array}$ & $\begin{array}{l}\text { Definition } \\
\text { study }\end{array}$ & $\begin{array}{l}\text { Global } \\
\text { design }\end{array}$ & $\begin{array}{l}\text { Detailed } \\
\text { design }\end{array}$ & Test phase \\
\hline System characteristics & G & D & & & \\
\hline Risk inventory & & G & D & & \\
\hline $\begin{array}{l}\text { Requirements of } \\
\text { security and control } \\
\text { - whole system } \\
\text { - subsystems }\end{array}$ & & G & D & G & \\
\hline $\begin{array}{l}\text { Measures of security } \\
\text { and control } \\
\text { (subsystems included) }\end{array}$ & & & G & D & \\
\hline $\begin{array}{l}\text { Testing (subsystems } \\
\text { included) }\end{array}$ & & & & & D \\
\hline
\end{tabular}

After the risk analysis is completed, the measures for covering the risks are specified. The results of this exercise are recorded in a document called the security chapter. This chapter is part of the detailed design.

The security chapter for TOP is specified in detail for the different subsystems and the quality criteria. Table 3 shows the matrix in which the relationship is given between the subsystems and the quality criteria. Table 4 presents a part of the detailed risk inventory for the Transaction-processing subsystem. The risk that is specified in detail is correctness and integrity. This is Scheme 2 from Table 3. 


\begin{tabular}{|c|c|c|c|c|c|c|c|c|}
\hline & 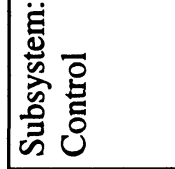 & 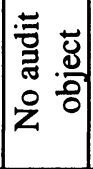 & 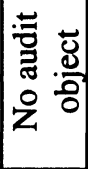 & 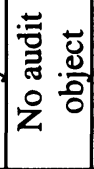 & 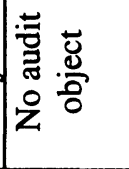 & 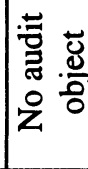 & 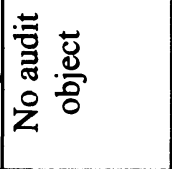 & 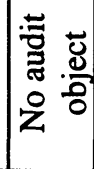 \\
\hline & 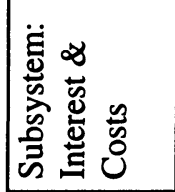 & 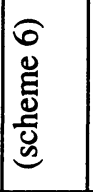 & 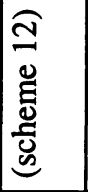 & 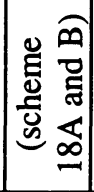 & 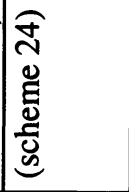 & 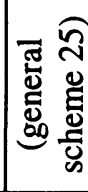 & 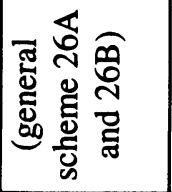 & 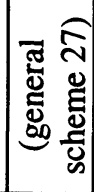 \\
\hline 를 & 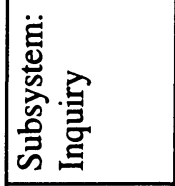 & 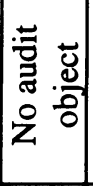 & 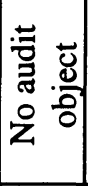 & 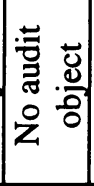 & 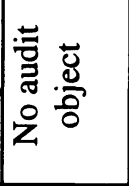 & 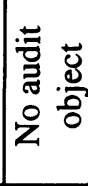 & 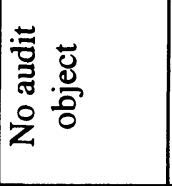 & 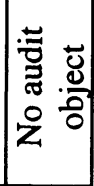 \\
\hline $\begin{array}{l}\frac{\text { ta }}{0} \\
0 \\
0 \\
0 \\
0 \\
0\end{array}$ & 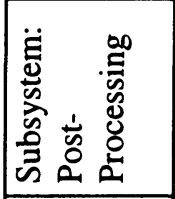 & 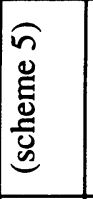 & 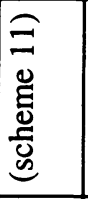 & 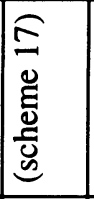 & 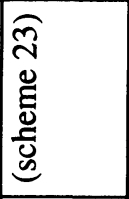 & 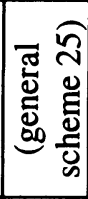 & 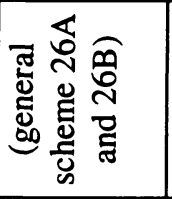 & 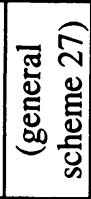 \\
\hline 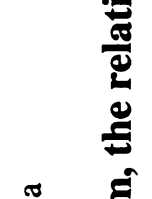 & 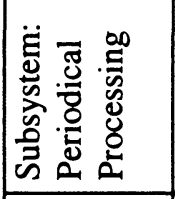 & 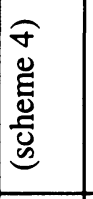 & 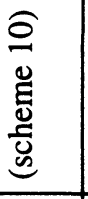 & 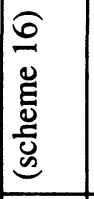 & 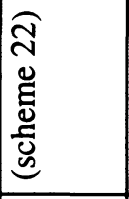 & 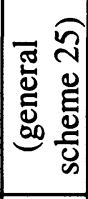 & 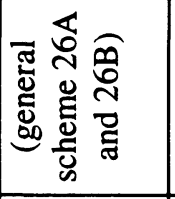 & 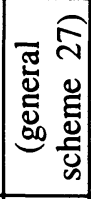 \\
\hline $\begin{array}{l}\frac{\Phi}{5} \\
\frac{0}{8} \\
\frac{0}{3} \\
0\end{array}$ & 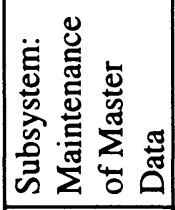 & 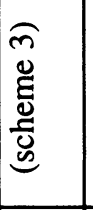 & 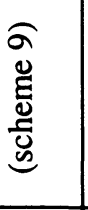 & 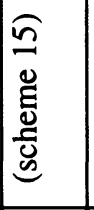 & 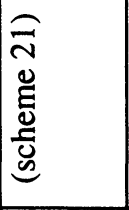 & 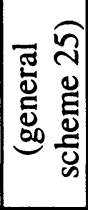 & 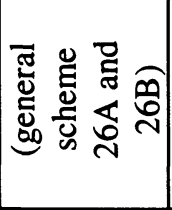 & 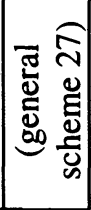 \\
\hline 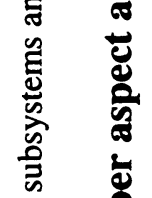 & 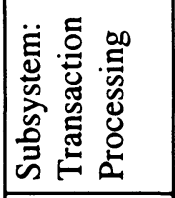 & 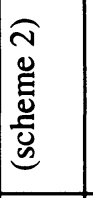 & 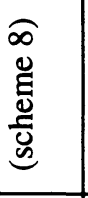 & 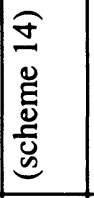 & 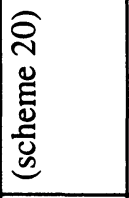 & 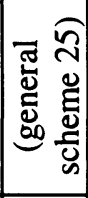 & 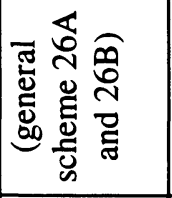 & 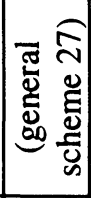 \\
\hline $\begin{array}{l}2 \\
0 \\
0 \\
0 \\
0 \\
0 \\
0\end{array}$ & 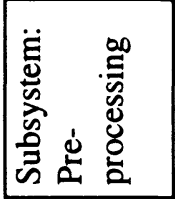 & 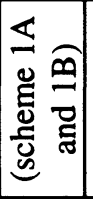 & 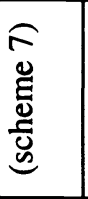 & 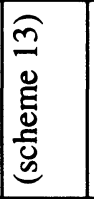 & 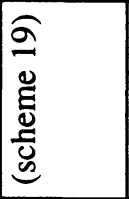 & 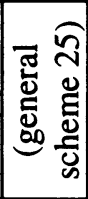 & 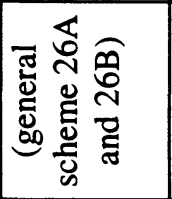 & 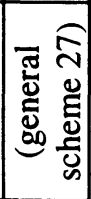 \\
\hline 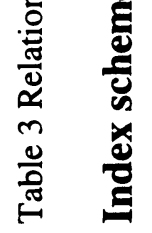 & & 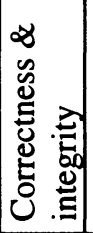 & 岁 & $\frac{\tilde{d}}{\frac{\tilde{d}}{0}}$ & 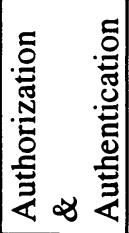 & 奞 & 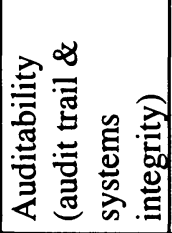 & 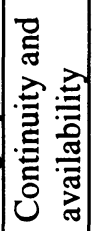 \\
\hline
\end{tabular}




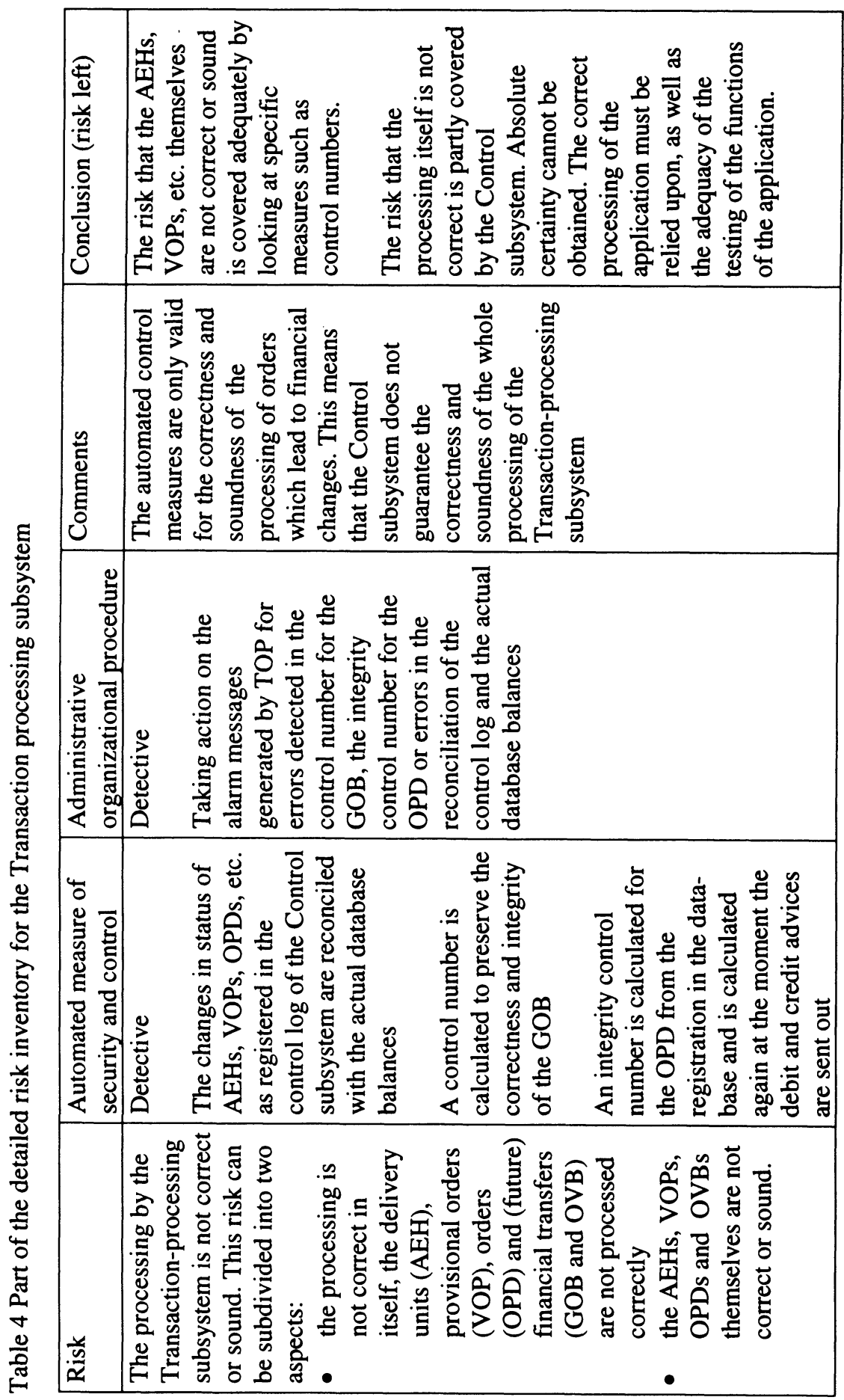




\section{Testing}

During the testing phase it is determined whether the measures of security and control are implemented in the application. Tests are performed by different employees of the Bank. Employees of the Automation Department System Development perform tests to determine whether the product they developed is in accordance with the specifications. The end-user tests to determine if the application operates in accordance with the specifications they have approved.

\section{CONTROL SUBSYSTEM}

\subsection{Objective of the Control subsystem}

The objective of the Control subsystem is to guarantee the reliability of TOP's transaction processing. Transaction processing includes all functions of TOP application with respect to:

- the receipt and registration of incoming messages in the TOP database,

- the processing of financial transactions, especially as regards account balances,

- the sending of output messages which are related to the above-mentioned functions.

\section{2 System characteristic}

The Control subsystem starts automatically at the beginning of every working day; it is one of the subsystems started first. The supervisor of TOP can influence the parameter setting which can affect the length of the interval between control runs. In normal situations the Control subsystem executes controls every half hour. During the day the Control subsystem can be switched off by making the length of the interval as long as the working day. However, the last control run will always be executed, it can not be switched off. The first and the last control run are extensive in the sense that all controls are executed. During the day, when every half hour controls are executed these will include a subset of the controls.

The possibility of changing the interval between the control runs has been implemented in the system because in the events of errors the user wants to have the time to solve the problem without the Control subsystem generating more warning messages. Changes in the parameter settings are audited by the internal control section of the Payments Department.

Every time that the Control subsystem executes the controls, a (limited) report is generated. This report consists of a few standard forms which can be read very easily (visual control at a single glance). When errors are detected the supervisor is informed, not only by the above-mentioned reports but also by a warning message which will be displayed on his terminal. The supervisor has to acknowledge the warning by using the Enter key. The warning messages are ranked from messages 
related to errors which do not have a great impact to messages related to errors which can have a great impact on the data in the database. The errors are specified in the reports.

The supervisor has to take adequate action on the basis of the warning messages. Errors detected by the Control subsystem never cause an automatic stop of TOP. This action has to be performed by the supervisor himself.

\subsection{Main parts of subsystem Control}

The Control subsystem consists of two main parts:
A. Control totals
B. Control log

\section{A. Control totals}

Based on the message-oriented character of the TOP application as a whole, where - via different media - incoming messages act as triggers for the transaction processes, the following description can be made:
A. incoming messages lead to registered delivery units (AEH);
B. delivery units lead to orders (OPD), in some cases through provisional orders (VOP) when the input has taken place via the TOP end station (TES);
C. orders (OPD) lead to financial transfers (OVB), future financial transfers (GOB) or actions on financial transactions or account data (e.g. an order to withdraw a future transfer);
D. on reaching the value date, future transfers lead to orders (OPD);
E. transfers, when inserted in a queue for settlement or processed in the cover of the account and/or settlement; lead to changes in the account processing data;
F. depending on specific circumstances the above-mentioned transaction processes lead to output messages at different moments.

These relations have been translated into the control totals, which are described as follows:

\section{Control totals $(I)-A E H$ versus $O P D$}

1. completeness of registered delivery units (AEH), when a AEH is registered the Control subsystem starts the control totals;

2. reconciliation between the approved and rejected AEH and the number of registered AEHs;

3. reconciliation between the number of orders (OPD) and AEHs;

4. reconciliation between the number of OPDs which are selected to different phases of processing and the total number of registered OPDs;

5. reconciliation between the number of approved provisional orders (VOP) and the number of OPDs which are input through the TOP end station. 
This part of the control totals is described in Section 4.

Control totals (II) - OPD versus $O V B / G O B$

6. reconciliation between number of orders (OPD) and number of financial transfers (OVB);

7. reconciliation between number of OPDs and number of future financial transfers (GOB);

8. reconciliation between number of GOBs which are transformed at value date and number of OVBs which are the result of this action;

9. reconciliation between number of withdrawals and cancelled OPDs and the number of cancelled OVBs and GOBs.

These control totals are described in Section 5.

Control totals (III) - account versus order

10. reconciliation amounts of financial transfers OVBs and the changes in account data (total control);

11. reconciliation amounts of OVBs and the changes in account data (controls in detail, per individual account);

12. consistency controls of individual accounts.

These control totals are described in Section 6.

Control totals (IV) - number of output messages versus number of processed OPDs

13. reconciliation between number of output messages and number of processed OPDs, OVBs and GOBs; control per type of output message

These control totals are described in Section 7.

Control totals $(V)$ - number of GOBs today versus previous day

14. reconciliation between the number of GOBs which are present today and the number of GOBs present at the end of the previous working day.

These control totals are described in Section 8.

Control totals (VI) - completeness of all output messages

15. completeness control of the processing of all output messages.

These control totals are described in Section 9.

The relations between the process flow and the controls mentioned above are the following: 
A. incoming messages lead to registered delivery units (AEH).

Controls 1 to 5

B. delivery units lead to orders (OPD), in some cases through provisional orders (VOP) when the input has taken place via the TOP end station (TES).

Controls 6 to 9

C. orders (OPD) lead to financial transactions - transfers (OVB) and future financial transfers (GOB) - or actions on financial transactions or account data (e.g. an order to withdraw a future transfer).

Controls 10 to 12

D. on reaching the value date, future transfers lead to orders (OPD).

Control 9

E. transfers when inserted in a queue for settlement or processed in the cover of the account and/or settlement, lead to changes in the account processing data.

Controls 10 to 12

F. depending on specific circumstances the transaction processes lead to output messages at different moments.

Control 15

\section{B. Control log}

The goal of this control is to determine that, at the moment the control run is executed, the actual (financial) balances have been completed in a reliable way. All of the primary processes that take place within the Pre-processing, Transactionprocessing and Post-processing subsystems write the actions they execute to a specific control log in the form of records. With every control run of the Control subsystem the control log is counted from the beginning and the totals are reconciled with the end balances of the TOP database at that moment.

\section{CONTROL TOTALS (I) - AEH VERSUS OPD}

\subsection{Goal}

In this part the control totals concerning the AEH and the OPD are specified in detail. The goal of this part of the control totals is as follows:

- today's registered AEHs are consistently classified into approved and rejected AEHs. The fact that an AEH is approved or rejected can be deduced from specific characteristics (attributes) which are checked by the Control subsystem; 
- the number of registered OPDs are in accordance with the number of approved AEHs;

- OPDs subduvided in various states of processing are in accordance with the number of AEHs;

- especially when viewed to medium of origin, reconciliation of number of registered OPDs via the TOP end station and the number of approved VOPs. The above-mentioned control totals are reproduced in the diagram presented in Table 5. This report is an example of one of the control reports generated by the Control subsystem and is a part of the actual report.

In the first column the transaction types are listed. In the columns A to $E$ the state of processing is specified. In column $F$ the totals of the columns $A$ to $F$ are presented. Table 5 shows a few of the possible transaction types. If a combination between row and column is not logical, a 'null' is presented.

\subsection{Description of the control totals}

Incoming messages which can contain financial orders are registered as Delivery units (AEH). The registration takes place in a new record in the DB2 table AEH. AEHs can be in the form of a message which contains one order or in the form of a batch or tape which can contain one or more orders. After the receipt of the message, batch or tape one of the controls that is executed is that TOP checks if the number of orders is in accordance with the information which is included in the batch or tape (header or trailer). The number of orders is registered in the record of the entity AEH (total of orders advised). The approval or rejection of the AEH is registered in the record concerning the $\mathrm{AEH}$. The reconciliation between the number of registered AEHs and the number of approved or rejected AEHs is presented in the second part of Table 5.

Next, the orders are individually checked on several points. Hereby the individual orders can be approved or rejected by TOP. The number of approvals or rejections is also registered in the record of the concerning AEH. Part 1 of table 5 presents the reconciliation between the total of advised orders which should be in the AEH and the number of approved or rejected orders. Also, a distinction is made between all the AEHs and the ones that are older than one hour. This is done because when a difference occurs between these numbers a signal is given to the supervisor that there is something wrong.

After the AEHs have been completly checked the approved orders are processed further. The AEHs are transformed into orders (OPD) which can be processed by the Transaction processing subsystem. The transformation is registered in the TOP database; a new record is written in the DB2 table OPD. The orders which are registered as OPD but are not yet processed further are presented in column $A$ of Part 3 of Table 5. After executing different controls by the Transaction processing subsystem an order can be approved or rejected. The number of rejected OPDs is 
presented in column B. The approved OPDs are processed further and the OPDs which are financial orders are thus transformed into financial transfers (OVB). The financial transfers which have a value date that is in the future are transformed into future financial transfers (GOB). The numbers of the financial transfers (OVB) are presented in column $\mathrm{C}$, the number of future financial transfers in column $\mathrm{D}$. The number of orders which are not financial transfers, such as pointing a transaction in front of the queue for settlement, are presented in column $\mathrm{E}$.

The total number of orders in the AEHs presented in Part 1 must be in accordance with the total number of today's registered OPDs, which are presented in column A in Part 3.

Table 5 Report of the Control subsystem, reconciliation AEH versus OPD

Part 1

Control attributes of entity AEH

- total number of orders in AEH approved

- total number of orders in AEH rejected

- total number of orders in AEH advised

G99 (all AEHs) G97 (AEHs older than 1 hour)

H99 (all AEHs) H97 (AEHs older than 1 hour)

199 (all AEHs) 197 (AEHs older than 1 hour)

Part 2

Control registration AEHs

Total today's registered AEHs

I98 (all AEHs) I96 (AEHs older than 1 hour)

- number approved

G98 (all AEHs) G96 (AEHs older

- number rejected than 1 hour)

H98 (all AEHs) H96 (AEHs older than 1 hour)

\section{Part 3}

\begin{tabular}{|l|l|l|l|l|l|l|}
\hline & Column A & Column B & Column C & Column D & Column E & Column F \\
\hline & $\begin{array}{l}\text { OPDs } \\
\text { registered } \\
\text { today and }\end{array}$ & $\begin{array}{l}\text { OPDs } \\
\text { registered } \\
\text { today and }\end{array}$ & $\begin{array}{l}\text { OPDs } \\
\text { registered } \\
\text { today and }\end{array}$ & $\begin{array}{l}\text { OPDs } \\
\text { registered } \\
\text { today and }\end{array}$ & $\begin{array}{l}\text { OPDs } \\
\text { registered } \\
\text { today and }\end{array}$ & $\begin{array}{l}\text { Totals of } \\
\text { today's } \\
\text { registered }\end{array}$ \\
\hline
\end{tabular}




\begin{tabular}{|c|c|c|c|c|c|c|}
\hline & $\begin{array}{l}\text { not yet } \\
\text { processed } \\
\text { by } \\
\text { Transaction } \\
\text { processing }\end{array}$ & \begin{tabular}{l|} 
rejected \\
today by \\
Transaction \\
processing
\end{tabular} & $\begin{array}{l}\text { processed } \\
\text { by } \\
\text { Transaction } \\
- \\
\text { processing: } \\
\text { approved } \\
\text { and OPD }\end{array}$ & $\begin{array}{l}\text { processed } \\
\text { by } \\
\text { Transaction } \\
\text { - } \\
\text { processing: } \\
\text { approved } \\
\text { and GOB }\end{array}$ & $\begin{array}{l}\text { processed } \\
\text { by } \\
\text { Transaction } \\
- \\
\text { processing: } \\
\text { approved } \\
\text { and } \\
\text { processed } \\
\text { (no OVB or } \\
\text { GOB) }\end{array}$ & $\begin{array}{l}\text { OPDs in } \\
\text { different } \\
\text { stages of } \\
\text { processing } \\
\text { Totals }\end{array}$ \\
\hline $\begin{array}{l}\text { Non-resident } \\
\text { payment MT } \\
100 \\
\end{array}$ & Al & B1 & $\mathrm{Cl}$ & D1 & Null & $\begin{array}{c}\mathrm{F} 1=\mathrm{A} 1+ \\
\mathrm{B} 1+\mathrm{C} 1+\mathrm{D} 1\end{array}$ \\
\hline $\begin{array}{l}\text { Non-resident } \\
\text { payment MT } \\
202\end{array}$ & A2 & B2 & $\mathrm{C} 2$ & D2 & Null & $\begin{array}{c}F 2=A 2+ \\
B 2+C 2+D 2\end{array}$ \\
\hline $\begin{array}{l}\text { Non-resident } \\
\text { payment MT } \\
205 \\
\end{array}$ & A3 & B3 & $\mathrm{C3}$ & D3 & Null & $\begin{array}{l}\mathrm{F} 3=\mathrm{A} 3+ \\
\mathrm{B} 3+\mathrm{C} 3+\mathrm{D} 3\end{array}$ \\
\hline $\begin{array}{l}\text { FA payment } \\
\text { MT } 100\end{array}$ & A4 & B4 & $\mathrm{C} 4$ & D4 & Null & $\begin{array}{c}\mathrm{F} 4=\mathrm{A} 4+ \\
\mathrm{B} 4+\mathrm{C} 4+\mathrm{D} 4\end{array}$ \\
\hline $\begin{array}{l}\text { FA payment } \\
\text { MT } 202\end{array}$ & A5 & B5 & $\mathrm{C} 5$ & D5 & Null & $\begin{array}{c}\mathrm{F} 5=\mathrm{A} 5+ \\
\mathrm{B} 5+\mathrm{C} 5+\mathrm{D} 5\end{array}$ \\
\hline $\begin{array}{l}\text { Withdrawal } \\
\text { GOB }\end{array}$ & A6 & B6 & C6 & D6 & Null & $\begin{array}{c}\mathrm{F} 6=\mathrm{A} 6+ \\
\mathrm{B} 6+\mathrm{C} 6+\mathrm{D} 6\end{array}$ \\
\hline $\begin{array}{l}\text { Approval } \\
\text { batch }\end{array}$ & A7 & Null & Null & Null & E7 & $\begin{array}{c}\mathrm{F} 7=\mathrm{A} 7+ \\
\text { E7 }\end{array}$ \\
\hline $\begin{array}{l}\text { Transaction } \\
\text { pointing }\end{array}$ & A8 & B8 & Null & Null & E8 & $\begin{array}{l}\mathrm{F} 8=\mathrm{A} 8+ \\
\mathrm{B} 8+\mathrm{E} 8\end{array}$ \\
\hline $\begin{array}{l}\text { Change of } \\
\text { space of } \\
\text { reserved cover }\end{array}$ & A9 & B9 & Null & Null & E9 & $\begin{array}{c}\mathrm{F} 9=\mathrm{A} 9+ \\
\mathrm{B} 9+\mathrm{E} 9\end{array}$ \\
\hline $\begin{array}{l}\text { Order without } \\
\text { check of } \\
\text { sufficient } \\
\text { cover }\end{array}$ & A10 & $\mathrm{B} 10$ & Null & Null & E10 & $\begin{array}{c}\mathrm{F} 10=\mathrm{A} 10 \\
+\mathrm{B} 10+ \\
\mathrm{E} 10\end{array}$ \\
\hline $\begin{array}{l}\text { Transaction } \\
\text { pointing by the } \\
\text { supervisor }\end{array}$ & A11 & Null & Null & Null & E11 & $\begin{array}{c}\mathrm{F} 11=\mathrm{A} 11 \\
+\mathrm{E} 11\end{array}$ \\
\hline Etc. & $\mathrm{An}$ & $\mathrm{Bn}$ & $\mathrm{Cn}$ & Dn & En & Fn \\
\hline & $\begin{array}{l}\text { Total } \\
\text { column } \mathrm{A}= \\
\mathrm{A} 1+\mathrm{A} 2+\mathrm{A} 3 \\
+\mathrm{A} 4+\mathrm{A} 5+ \\
\mathrm{A} 6+\mathrm{A} 7+\mathrm{A} 8 \\
+\mathrm{A} 9+\mathrm{A} 10+ \\
\mathrm{A} 11+\mathrm{An} . .\end{array}$ & $\begin{array}{l}\text { Total } \\
\text { column B = } \\
\mathrm{B} 1+\mathrm{B} 2+ \\
\mathrm{B} 3+\mathrm{B} 4+ \\
\mathrm{B} 5+\mathrm{B} 6+ \\
\mathrm{B} 8+\mathrm{B} 9+ \\
\mathrm{B} 10+\mathrm{Bn}\end{array}$ & $\begin{array}{l}\text { Total } \\
\text { column } \mathrm{C}= \\
\mathrm{C} 1+\mathrm{C} 2+ \\
\mathrm{C} 3+\mathrm{C} 4+ \\
\mathrm{C} 5+\mathrm{C} 6+ \\
\mathrm{Cn} .\end{array}$ & $\begin{array}{l}\text { Total } \\
\text { column D } \\
= \\
\text { D1 + D2 + } \\
\text { D3 + D4 + } \\
\text { D5 + D6 + } \\
\text { Dn... }\end{array}$ & $\begin{array}{l}\text { Total } \\
\text { column } \mathrm{E}= \\
\mathrm{E} 7+\mathrm{E} 8+ \\
\mathrm{E} 9+\mathrm{E} 10+ \\
\mathrm{E} 11+ \\
\text { En... }\end{array}$ & $\begin{array}{l}\text { Total } \\
\text { general } \\
\text { Rows F1 to } \\
\text { Fn = totals } \\
\text { Columns } \\
\text { A to E }\end{array}$ \\
\hline
\end{tabular}




\section{CONTROL TOTALS (II) - OPD VERSUS OVB/GOB}

\subsection{Goal}

In this part the control totals between the order (OPD) and the financial transfer (OVB) or future financial transfer (GOB) are specified in detail. The goal of this part is to check that:

- the number of today's registered OPDs is in accordance with the number of financial transfers (OVB) or future financial transfers (GOB);

- the reconciliation between the OVBs and GOBs - subdivided into different stages of processing - and the calculated control totals for both numbers and amounts.

- the withdrawn and cancelled financial transfers are only the result of specific present and registered orders.

The above-mentioned control totals are reproduced in the diagram presented in Table 6. An order can be processed in different ways. The way an order is handled depends on different criteria. In the first column the different ways of handling an order are presented.

\subsection{Description of the control total}

After an incoming message has been accepted by TOP and transformed into an order, the processing continues by transforming the order into a financial transfer (OVB) with a value date of today or into a future financial transfer (GOB) with a value date which lies in the future.

On every new working day when TOP starts the future financial transfers are checked on the value date. When the value date of the future financial transfer is the same as the actual value date it is transformed into an order (OVB). If the value date of the financial future transfer is later then the actual value date it remains a GOB. It is also possible that a GOB is rejected by TOP, for example because the information in the GOB is conflicting with master data. The state of processing of the GOBs is presented in columns $\mathrm{J}$ to $\mathrm{P}$ in Figure 4.

The financial transfers (OVB) are processed further in that the check of sufficient cover is executed for the account to be debited. If there is enough cover the financial transfer is settled. If the cover is not sufficient the transfer is placed in a queue. The moment the cover is changed and is sufficient to settle the first transfer in the queue, settlement will take place. It is also possible that the cover is blocked and the final settlement will take place at a later moment. The state of processing of the OVBs is presented in the columns $\mathrm{Q}$ to $\mathrm{R}$. The report generated by the Control subsystem contains more columns and rows, in fact, but has been shortened for this paper. 
The control totals are calculated for the number of transactions as well as the totals of the amounts of the concerning transactions. It is checked whether:

- the totals of the numbers and amounts of OVBs and GOBs are only in the rows and columns where, logically they can only be present;

- the totals for both the numbers and the amounts on the axes of the matrix (column $\mathrm{ZZ}$ and the totals at the bottom of the columns) correspond. 


\begin{tabular}{|c|c|c|c|c|c|c|}
\hline 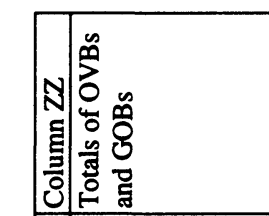 & $\frac{\pi}{n} \bar{a}$ & 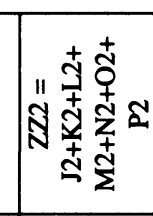 & $\sqrt[4]{2}$ & 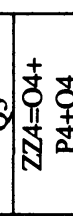 & $\mid \begin{array}{l}n \\
0 \\
3 \\
3\end{array}$ & 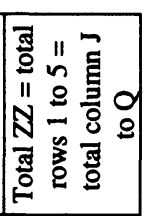 \\
\hline 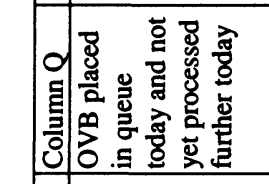 & $\bar{\alpha}$ & 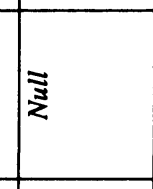 & $\approx$ & t & $\approx$ & 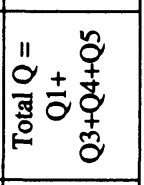 \\
\hline 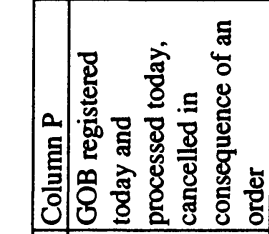 & $\approx$ & $\Sigma$ & $\bar{z}$ & I & $\bar{z}$ & 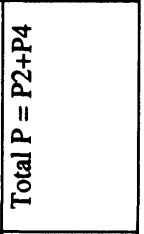 \\
\hline 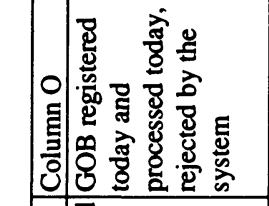 & $\bar{\Xi}$ & $\delta$ & $\bar{\Xi}$ & ठ & $\bar{\Sigma}$ & |l \\
\hline 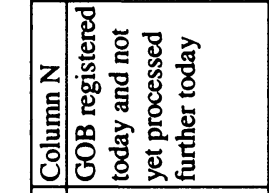 & $\bar{\xi}$ & $\tilde{z}$ & 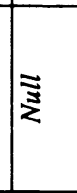 & $\bar{z}$ & $\bar{\xi}$ & 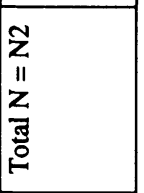 \\
\hline 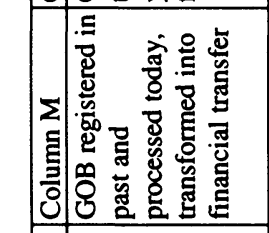 & $\bar{\Xi}$ & $\tilde{\Sigma}$ & $\bar{z}$ & $\bar{\Xi}$ & $\bar{\xi}$ & 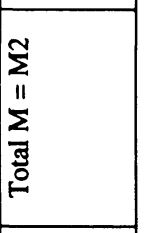 \\
\hline 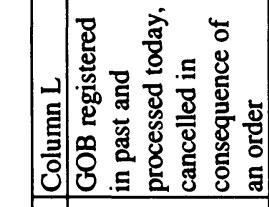 & z & $\Im$ & 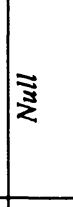 & $\bar{\Xi}$ & $\bar{z}$ & 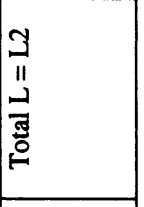 \\
\hline 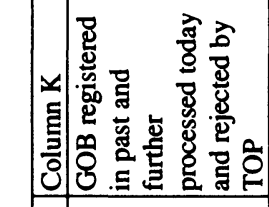 & z & $\mathscr{x}$ & 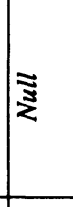 & $\$$ & $\bar{\xi}$ & 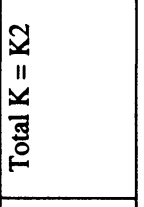 \\
\hline 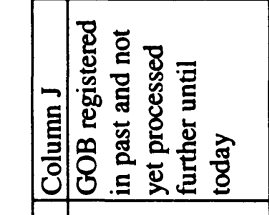 & $\bar{\Xi}$ & $\simeq$ & 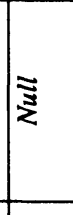 & 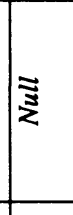 & $\bar{z}$ & 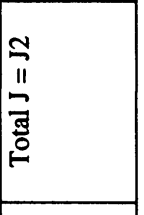 \\
\hline & 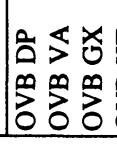 & 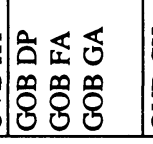 & 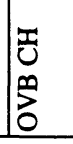 & $\begin{array}{l}5 \\
j \\
\text { s } \\
0\end{array}$ & 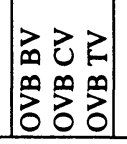 & \\
\hline
\end{tabular}




\section{CONTROL TOTALS (III) - ACCOUNT VERSUS ORDER}

\subsection{Goal}

These control totals are subdivided into a limited version and an extensive version. Both versions check the same data. The limited version is executed during the working day, the extensive version is executed at the end of the working day. The controls in the extensive version are more detailed.

The goal of these controls is that the amounts in the financial transfers as registered in the TOP-database are in accordance with the process data concerning the accounts. Partly for performance reasons a few fields are kept with data which is often used by TOP. The data in these fields is kept up to date to prevent TOP calculating the wanted data again and again.

\subsection{Description of the control totals}

The report which is generated by the Control subsystem is presented in Table 7.

Table 7 Report of the Control subsystem, reconciliation account versus order

\begin{tabular}{|c|c|c|}
\hline & $\begin{array}{c}\text { Contents of } \\
\text { account (REK) } \\
\text { control totals }\end{array}$ & $\begin{array}{l}\text { Contents of financial } \\
\text { transfers (OVB) } \\
\text { control totals }\end{array}$ \\
\hline $\begin{array}{l}\text { Sum opening balance } \\
\text { Sum settled debit } \\
\text { Sum settled credit } \\
\text { Sum balances }\end{array}$ & $\begin{array}{l}\text { Amount } \\
\text { Amount } \\
\text { Amount } \\
\text { Amount }\end{array}$ & $\begin{array}{l}\text { Amount } \\
\text { Amount }\end{array}$ \\
\hline $\begin{array}{l}\text { Sum queue (number) } \\
\text { Sum queue debit (today) } \\
\text { Sum queue credit (today) } \\
\text { Sum queue debit (future) }\end{array}$ & $\begin{array}{l}\text { Number } \\
\text { Amount } \\
\text { Amount } \\
\text { Amount }\end{array}$ & $\begin{array}{l}\text { Number } \\
\text { Amount } \\
\text { Amount } \\
\text { Amount }\end{array}$ \\
\hline $\begin{array}{l}\text { Sum processed in cover } \\
\text { debit (today) } \\
\text { Sum processed in cover } \\
\text { credit (today) } \\
\text { Sum processed in cover } \\
\text { debit (future) }\end{array}$ & $\begin{array}{l}\text { Amount } \\
\text { Amount } \\
\text { Amount }\end{array}$ & $\begin{array}{l}\text { Amount } \\
\text { Amount } \\
\text { Amount }\end{array}$ \\
\hline $\begin{array}{l}\text { Sum of credit facility } \\
\text { Sum cover }\end{array}$ & $\begin{array}{l}\text { Amount } \\
\text { Amount }\end{array}$ & \\
\hline
\end{tabular}


The first part of the report contains two controls. The first is the control to reconcile the opening balances, the settled amounts debit and credit and the closing balances. Debit and credit must always be the same as the total amount of the opening and closing balances. The settled amounts debit and credit are also compared with the information registered for the financial transfers (OVB). The second part of the report reconciles the number of transactions which are queued and the sum of the amounts to be debited or credited today and the amounts to be debited in the future. The information registered in the database for the accounts (REK) is reconciled with the information registered in the database for the financial transfers (OVB). In Table 7, the amounts presented are the total for all the accounts and financial transfers when the limited version is executed. The report generated when the extensive version is executed gives the same information but then the totals are presented for all the individual accounts.

\section{CONTROL TOTALS (IV) - NUMBER OF OUTPUTMESSAGES VERSUS NUMBER OF PROCESSED OPD'S}

\subsection{Goal}

The goal of this control is to, during the last run of subsystem Control, reconciliate for a number of types of outputmessages that the numbers which are sent are equal to the number in the database. This control is executed only at the end of the day.

\subsection{Description of the control total}

Table 8 presents the report which is generated. In fact, Table 8 only shows the part of the report which is generated by the Control subsystem. In the report, the reconciliation is presented between received transactions and the output messages which are the result of the processing. The first part presents the reconciliation between the number of settled transactions and the number of debit and credit advices sent. All three must be identical. The number of settled transactions should correspond with the number of settled transactions presented in Table 5.

In the second part the reconciliation is presented for the non-processed transactions. Non-processed means that the transactions have been cancelled or rejected, i.e. no settlement has taken place. For future transfers, the number of received transactions is presented. The received transactions are subdivided into received via SWIFT, MQM or TES and created by TOP. The number of transactions received via SWIFT, MQM or TES must correspond with the number of output messages of type 1518, the number of transactions created by TOP. The number of received future transfers must correspond with the number presented in N2 in Table 6. 
Table 8 Report of the Control subsystem, number of output messages versus number of transaction processed

Processed transactions

Settled transactions $(\mathrm{Z}+\mathrm{AA})$

Debit advices sent

Number

Credit advices sent

Number

Number

Non-processed transactions

Future transfers

Received (N2)

Via SWIFT, MQM, TES

Number

Number

Message type 1518

Number

Created by TOP

Message type 1535

Number

Number

Cancelled (K2+L2+O2+P2)

Number

Message types $1511,1516,1525$

Number

Of which by message type 1006 (E6)

Number

Message type 1516

Of which others

Message types 1511,1525

Number

Number

Number

Rejected (B4+B5+B17)

Number

Message type 1509

Number

Non-resident payments $(\mathrm{B} 1+\mathrm{B} 2+\mathrm{B} 3)$

Number

Message type 1528

Number

Withdrawals (B6)

Number

Message type 1508

Number 


\section{CONTROL TOTALS (V) - NUMBER OF GOBS TODAY VERSUS PREVIOUS DAY}

\subsection{Goal}

The goal of this control is to reconcile the number and amount of future transfers which where present at the end of the previous working day and the number and amount of future transfers present at the beginning of the next working day.

\subsection{Description of the control total}

The control is executed by selecting the future transfers in the actual database which were present or should have been present at the end of the previous working day. On the other hand, the future transfers which will be present at the beginning of the next working day are selected during the last run of the Control subsystem. The result of the control is presented in Table 9.

Table 9 Control report by the Control subsystem on overnight reconciliation

\begin{tabular}{|l|c|c|c|c|}
\hline & Old & Old & New & New \\
\hline Future & J2 & J2 & J2 & Number \\
transfers & K2 & K2 & N2 & Number \\
& L2 & L2 & & \\
& M2 & M2 & & \\
& Total & Total & Total & Number \\
\hline Future & J2 & Amount & J2 & Amount \\
transfers & K2 & Amount & N2 & Amount \\
& L2 & Amount & & \\
& M2 & Amount & & \\
& & & & \\
& Total & Amount & Total & Amount \\
\hline
\end{tabular}

This report should be checked visually by the supervisor by checking the columns which present the numbers and amounts of the previous working day with the corresponding columns of the report of the previous working day. 


\section{CONTROL TOTALS (VI) - COMPLETENESS OF OUTPUT MESSAGES}

The goal of this control is to ensure that all output messages were really sent. This must be checked before the working day can be closed by the Periodical processing subsystem. In the report generated by the Control subsystem the number of output messages made by TOP is presented, as well as the number of output messages sent.

Table 10 Report reconciliation of output messages sent

\begin{tabular}{|l|l|}
\hline Output messages generated & Number \\
\hline Output messages sent & Number \\
\hline Difference & Number \\
\hline
\end{tabular}

The supervisor has to check visually that there is no difference between these numbers.

\section{CONTROL LOG}

\subsection{Goal}

The goal of this control is to determine that, at the moment the control run is executed, the actual (financial) balances have been completed in a reliable way. The (financial) balances comprise

- the number of provisional orders (VOP), orders (OPD), financial transfers (OVB), future financial transfers (GOB), output results (URE) and output units (UEH);

- the transaction amounts for the financial transfers (OVB) and future financial transfers (GOB).

By 'completed in a reliable way' is meant that:

- the transactions are caused only by authorized user and system functions

- the actual balances have been reconciled with the balances at the end of the last working day, including the transactions which were input today,.

\subsection{Description of the control total}

All of the primary processes that take place within the Pre-processing, Transactionprocessing and Post-processing subsystems write the actions they execute to a specific control log in the form of records. Such a record comprises both the old situation (before the processing has taken place) and the new situation (after the processing has taken place). For every order (OPD), transfer (OVB) and future transfer $(\mathrm{GOB})$ the operation is registered in the form of a so-called status change. The starting situation is referred to by 'status old', the end situation by 'status new'. A record in the control log contains two statuses, an event can be completely 
described in the form of a status change. The history can be described by putting alle status changes after each other.

The control measure means that with every control run of the Control subsystem, during the day as well as at the end of the day, the control log is counted from the beginning. Thus, based on the individual log records, the end balances are calculated which should be presented in the actual TOP database. These end balances are in total numbers; for the (future) financial transfers they are also in total amounts per status. Next, the calculated ending balances are reconciled with the end balances of the TOP database at that moment.

A special control is the use of the control log for the control of the transactions which are input via the TOP endstation. The control log is used to check, not on an individual basis but in totals, that only authorized actions have taken place by users actually logged on. The changes in numbers and in the status of the VOPs and OPDs are in accordance with the control log.

Table 11 Reconciliation between Control log and ending balances in the database

\begin{tabular}{|c|c|c|c|c|}
\hline $\begin{array}{c}\text { Count of status } \\
\text { and advices }\end{array}$ & $\begin{array}{l}\text { According } \\
\text { to }\end{array}$ & $\begin{array}{l}\text { According } \\
\text { to }\end{array}$ & Numbers & Amounts \\
\hline TA & STO & $\begin{array}{l}\text { TAA } \\
\text { TAX } \\
\end{array}$ & $\mathrm{j}$ & $\mathrm{n}$ \\
\hline TU & STO & $\begin{array}{l}\text { TAA } \\
\text { TUX }\end{array}$ & $\mathrm{j}$ & $\mathrm{n}$ \\
\hline TI & STO & $\begin{array}{l}\text { TAA } \\
\text { TIX }\end{array}$ & $\mathrm{j}$ & $\mathrm{n}$ \\
\hline IN & STO & VOP & $j$ & $\mathrm{n}$ \\
\hline $\mathrm{TF}$ & STO & $\begin{array}{l}\text { VOP } \\
\text { TFX }\end{array}$ & $\mathrm{j}$ & $\mathrm{n}$ \\
\hline TV & STO & $\begin{array}{l}\text { VOP } \\
\text { TVX }\end{array}$ & $\mathrm{j}$ & $\mathrm{n}$ \\
\hline TW & STO & TWX & $j$ & $\mathrm{n}$ \\
\hline ON & STO & VOP & $\mathrm{j}$ & $\mathrm{n}$ \\
\hline OV & STO & OPD & $\mathrm{j}$ & $\mathrm{n}$ \\
\hline AT & STO & OPD & $j$ & $\mathrm{n}$ \\
\hline IU & STO & OPD & $\mathrm{j}$ & $\mathrm{n}$ \\
\hline GO & STO & GOB & $j$ & $j$ \\
\hline WR & STO & OVB & $\mathrm{j}$ & $j$ \\
\hline OP & STO & $\begin{array}{l}\text { OVB } \\
\text { GOB }\end{array}$ & $\mathrm{j}$ & $\mathrm{j}$ \\
\hline VD & STO & OVB & $j$ & $j$ \\
\hline SE & STO & OVB & $j$ & $j$ \\
\hline Debit advices & & DBA & $j$ & $\mathrm{n}$ \\
\hline
\end{tabular}


described in the form of a status change. The history can be described by putting alle status changes after each other.

The control measure means that with every control run of the Control subsystem, during the day as well as at the end of the day, the control log is counted from the beginning. Thus, based on the individual log records, the end balances are calculated which should be presented in the actual TOP database. These end balances are in total numbers; for the (future) financial transfers they are also in total amounts per status. Next, the calculated ending balances are reconciled with the end balances of the TOP database at that moment.

A special control is the use of the control log for the control of the transactions which are input via the TOP endstation. The control log is used to check, not on an individual basis but in totals, that only authorized actions have taken place by users actually logged on. The changes in numbers and in the status of the VOPs and OPDs are in accordance with the control log.

Table 11 Reconciliation between Control log and ending balances in the database

\begin{tabular}{|c|c|c|c|c|}
\hline $\begin{array}{l}\text { Count of status } \\
\text { and advices }\end{array}$ & $\begin{array}{l}\text { According } \\
\text { to }\end{array}$ & $\begin{array}{l}\text { According } \\
\text { to }\end{array}$ & Numbers & Amounts \\
\hline $\mathrm{TA}$ & STO & $\begin{array}{l}\text { TAA } \\
\text { TAX }\end{array}$ & $\mathrm{j}$ & $\mathrm{n}$ \\
\hline TU & STO & $\begin{array}{l}\text { TAA } \\
\text { TUX }\end{array}$ & $\mathrm{j}$ & $\mathrm{n}$ \\
\hline TI & STO & $\begin{array}{l}\text { TAA } \\
\text { TIX }\end{array}$ & $\mathrm{j}$ & $\mathrm{n}$ \\
\hline IN & STO & VOP & $j$ & $n$ \\
\hline $\mathrm{TF}$ & STO & $\begin{array}{l}\text { VOP } \\
\text { TFX }\end{array}$ & j & $\mathrm{n}$ \\
\hline TV & STO & $\begin{array}{l}\text { VOP } \\
\text { TVX }\end{array}$ & $\mathrm{j}$ & $\mathrm{n}$ \\
\hline TW & STO & TWX & $j$ & $\mathrm{n}$ \\
\hline ON & STO & VOP & $j$ & $\mathrm{n}$ \\
\hline OV & STO & OPD & $\mathrm{j}$ & $\mathbf{n}$ \\
\hline AT & STO & OPD & $j$ & $\mathrm{n}$ \\
\hline IU & STO & OPD & $j$ & $\mathrm{n}$ \\
\hline GO & STO & GOB & $j$ & $j$ \\
\hline WR & STO & OVB & $j$ & $j$ \\
\hline OP & STO & $\begin{array}{l}\text { OVB } \\
\text { GOB }\end{array}$ & $\mathrm{j}$ & $\mathrm{j}$ \\
\hline VD & STO & OVB & $j$ & $j$ \\
\hline SE & STO & OVB & $\mathrm{j}$ & $j$ \\
\hline Debit advices & & DBA & i & $n$ \\
\hline
\end{tabular}




\begin{tabular}{|c|c|c|c|c|}
\hline Credit advices & & CRA & j & n \\
\hline AN & STO & URE & j & n \\
\hline GL & STO & URE & j & n \\
\hline
\end{tabular}

Explanation status
AN $=$ rejected by the Post-processing subsystem
$\mathrm{AT}=$ rejected by the Transaction processing subsystem
$\mathrm{GL} \quad=$ delivered
$\mathrm{GO}=$ approved
IN = input by the Post-processing subsystem
IU $=$ withdrawal executed
ON = cancelled by the Post-processing subsytem
$\mathrm{OP} \quad=$ (future) financial transfer cancelled
$\mathrm{OV}=$ received from the Pre-processing subsystem
$\mathrm{SE} \quad=$ settled
$\mathrm{TA}=$ logged on on TOP end station
TI $=$ input via TES
$\mathrm{TF} \quad=$ approved via TES
TU $=$ logged off of TES
$\mathrm{TV}=$ cancelled via TES
TW $=$ changed via TES
$\mathrm{VD}=$ processed in the cover
$\mathrm{WR}=$ placed in queue

\section{BIOGRAPHY}

Marcel Korver is working as an EDP-auditor at the Internal Audit Department of the Dutch Central Bank. He has graduated in accountancy from the 'Koninklijke Nederlands Instituut van Registeraccountants' in 1990. In 1993 he graduated in EDP-auditing from the Erasmus University. 